\title{
Esplenose Torácica: um achado acidental mais de 20 anos após traumatismo toraco-abdominal
}

\author{
Thoracic splenosis: an incidental finding \\ more than 20 years after thoraco-abdominal trauma
}

\begin{abstract}
Helena Martins ${ }^{1}$, Gillberto Teixeira², Lília Andrade ${ }^{3}$, Alcina Saraiva ${ }^{4}$
${ }^{1}$ Interna de Formação Específica de Medicina Interna, Serviço de Medicina Interna,Centro Hospitalar do Baixo Vouga, E.P.E Aveiro, Portugal. ${ }^{2}$ Assistente Hospitalar de Pneumologia, Serviço de Pneumologia, do Centro Hospitalar do Baixo Vouga, E.P.E Aveiro, Portugal. ${ }^{3}$ Assistente Hospitalar de Pneumologia, Serviço de Pneumologia, do Centro Hospitalar do Baixo Vouga, E.P.E Aveiro, Portugal. ${ }^{4}$ Assistente Hospitalar de Pneumologia, Diretora do Serviço de Pneumologia do Centro Hospitalar do Baixo Vouga, E.P.E Aveiro, Portugal.
\end{abstract}

\section{RESUMO}

A esplenose torácica é uma condição rara, benigna que resulta da rutura do baço associada ou não a lesão do diafragma, geralmente assintomática e acidentalmente diagnosticada após a realização de exames de imagem por qualquer outro motivo. Apresentamos o caso clínico de um homem de 45 anos de idade, assintomático, com antecedentes de traumatismo do baço consequente a um acidente de viação aos 18 anos de idade. 0 doente foi enviado a consulta de Pneumologia por achados imagiológicos compatíveis com nódulos pleurais no hemitórax esquerdo, mas a análise histopatológica das referidas lesões demonstrou tratar-se de tecido esplénico. 0 tratamento dos remanescentes esplénicos é conservador. Estes podem adquirir função imunológica, independentemente do local onde estão implantados, e proteger o organismo de eventuais infeções. Palabras clave: esplenosis torácica, trauma esplénico, hallazgos de imágenes, gammagrafía pulmonar

\section{INTRODUÇÃO}

Em 1910 Von Kutner identificou pela primeira vez implantes de tecido esplénico na cavidade peritoneal após rutura traumática do baço. ${ }^{1,2,3}$

A Esplenose é uma condição benigna, extremamente rara, definida como a autotransplantação heterotópica de fragmentos de tecido esplénico, que ocorre habitualmente após laceração do baço com rotura da sua cápsula, devido a trauma ou após manipulação cirúrgica do órgão, tal como acontece na esplenectomia eletiva. ${ }^{1,4,5,6,7,8,9}$

Os implantes de tecido esplénico, em forma de nódulos encapsulados, surgem mais frequentemente nas cavidades abdominal e pélvica, mas também podem ser extra-peritoneais. Existem relatos de casos de baços ectópicos localizados na cavidade pleural, parênquima pulmonar, pericárdio, tecido subcutâneo e cérebro. 4, 6,7,8

A Esplenose torácica é geralmente assintomática, sendo frequentemente um achado acidental, diagnosticada na sequência de exames imagiológicos de rotina. No entanto, a sua presença pode originar sintomas como dor e hemorragia mimetizando diversas patologias tais como neoplasias, incluindo o carcinoma broncogénico, linfoma, mesotelioma e timoma, metástases pleurais e asbestose. . $^{10,11}$

\section{SUMMARY}

Thoracic splenosis is a rare, benign condition that results from the rupture of the spleen associated or not to diaphragm injury, usually asymptomatic and incidentally diagnosed after performing imaging exams for other reasons. We present the case of a 45 -year-old male, asymptomatic, with splenic trauma history subsequent to a traffic accident at 18 years of age. The patient was sent to Pneumology consultation due to imaging findings consistent with pleural nodules in the left hemithorax, but histopathological examination of these lesions showed the presence of splenic tissue. The treatment of splenic remnants is conservative. These can acquire immune function, regardless of their location, and protect the patient from possible infections.

Keywords: thoracic splenosis, splenic trauma, imaging findings, pulmonary scintigraphy

A incidência da Esplenose tem vindo a aumentar nos últimos anos e estima-se que possa atingir os $76 \%{ }^{7}$ Contudo, Normand et al, em 1993, já referiam que a Esplenose intratorácica era uma entidade bastante rara, ocorrendo apenas em 18\% dos doentes vítimas de traumatismo toraco-abdominal com rutura simultânea do baço e diafragma. ${ }^{6,9,10,12}$

Atualmente estão publicados 54 casos de Esplenose torácica na literatura Inglesa, no entanto, a incidência global desta patologia permanece desconhecida provavelmente devido à escassez de casos relatados na literatura., ${ }^{1,5,6}$

0 tempo médio decorrido desde 0 evento traumático inicial e o diagnóstico da doença é frequentemente prolongado, cerca de 18,8 anos, o que reflete um crescimento lento do tecido esplénico. 3,4,5,7, 10

0 exame Gold Standard para o diagnóstico desta patologia é a cintilografia utilizando o tecnécio-99m (99m-TC) como contraste, um método não invasivo que permite um diagnóstico precoce evitando intervenções cirúrgicas desnecessárias. 1,5,7,13

\section{CASO CLÍNICO}

Os autores apresentam o caso clinico de um homem, de 45 anos de idade, raça caucasiana, assintomático, que foi enviado à consulta de Pneumologia por alterações radiológicas em exames de rotina [telerradiografia torácica e tomografia computorizada (TC) torácica] compatíveis com nódulos pleurais no hemitórax esquerdo. 

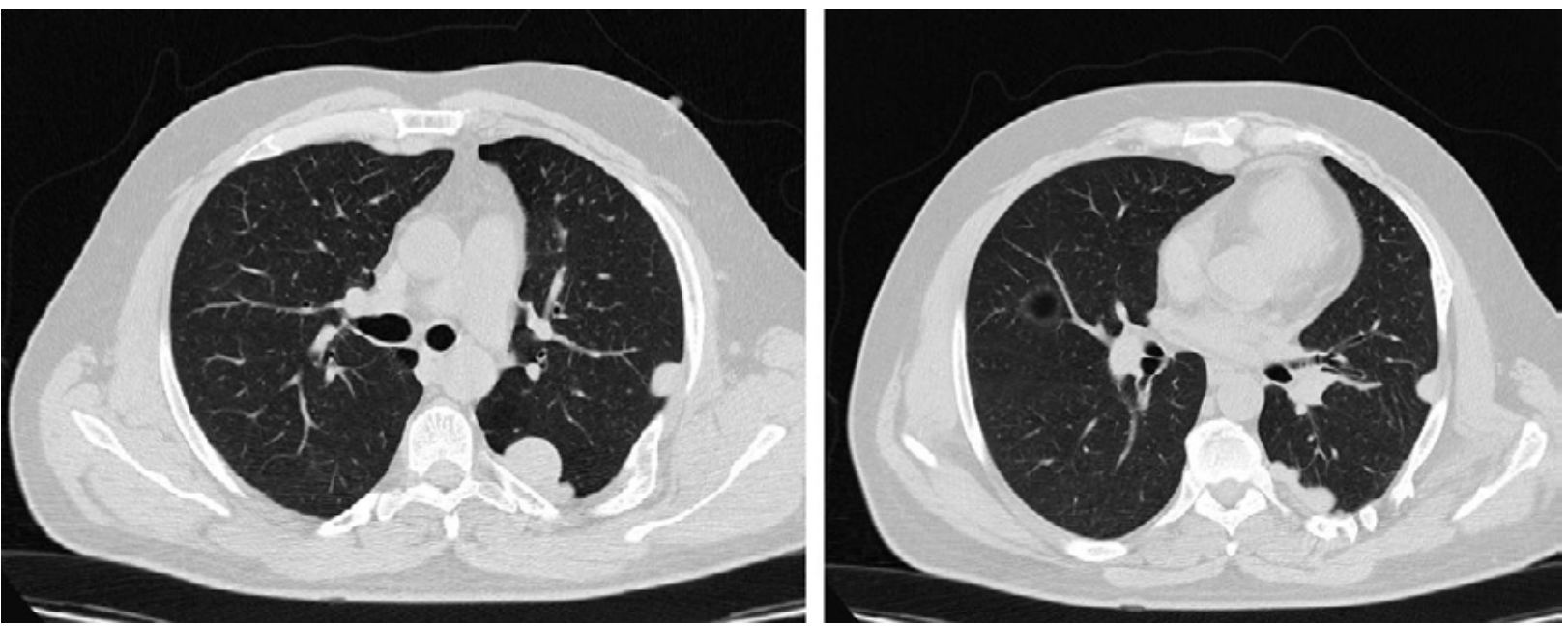

0 doente apresentava como antecedentes pessoais de relevo, história de um acidente de viação aos 18 anos, com traumatismo toraco-abdominal e fratura de cinco costelas à esquerda.

Ao exame objetivo, eram palpáveis adenomegalias axilares bilaterais. 0 doente era portador de TC torácica de ambulatório que evidenciava pequenas estruturas ganglionares paratraqueais e axilares, assim como várias formações nodulares sólidas da pleura, a maior das quais com 30 mm de diâmetro (Fig. 1 - nódulos pleuropulmonares). Para esclarecimento dessas lesões, o doente efetuou punção aspirativa da massa pleural cuja citologia revelou a presença de "linfócitos". Seguidamente foi proposto e aceite para Cirurgia Cardíaca com vista a esclarecimento diagnóstico. Realizou biópsia cirúrgica da massa pleural por videotoracoscopia, para despiste de eventual Linfoma, uma vez que o linfoma pleural, observado quer em doentes com doença de Hodgkin ou não-Hodgkin, pode manifestar-se como múltiplos nódulos pleurais. ${ }^{9}$ Contudo, a análise histopatológica da amostra ressecada foi compatível com tecido esplénico (Fig. 2 tecido esplénico observado na peça cirúrgica).

\section{DISCUSSÃO}

A Esplenose torácica ocorre menos frequentemente do que a abdominal e representa sequelas de rutura do baço associada ou não a lesão diafragmática, a qual permite implantação de tecido esplénico na cavidade pleural esquerda. 1,9

Os sintomas da Esplenose torácica podem ocasionalmente causar dor pleurítica, hemoptises, dor tipo "enfarte do miocárdio", febre de origem desconhecida, obstrução ou isquemia intestinal, massa abdominal ou pélvica, dor no flanco por compressão ureteral e hidronefrose, tratando-se nestes casos de esplenose com localização abdominal. ${ }^{7}$ Contudo, a maioria dos doentes é assintomática e a doença é descoberta acidentalmente, assim como se verificou no caso em que descrevemos. ${ }^{1,7,9}$

A TC tórax revela um nódulo solitário na base da pleura ou uma massa em $25 \%$ dos casos e múltiplos nódulos pleurais em $75 \%$ dos casos restantes. ${ }^{14}$ Reveste-se de grande importância este exame de imagem, sobretudo nos casos que surgem como incidentalomas.
0 caso apresentado de esplenose torácica demonstra os achados acidentais da TC, correspondentes a vários nódulos dispersos no espaço pleural localizados no hemitórax esquerdo. Efetivamente, os implantes frequentemente aparecem como pequenos nódulos pleurais ou subpleurais mas podem ser maiores e intraparenquimatosos. ${ }^{1} 0$ caso que apresentamos não possuía lesões no parênquima pulmonar.

0 tecido esplénico implantado é capaz de crescer e reestabelecer circulação, tornando-se funcional, isto é, adquire capacidade imunológica, o que está relacionado com a quantidade de tecido ectópico envolvido. Por consequência protege o organismo de possíveis infeções. ${ }^{1,7}$

Os achados analíticos são inespecíficos, no entanto a presença de tecido esplénico autotransplantado pode ser sugerido por achados laboratoriais como anisocitose, poiquilocitose e a presença de corpos de Howell-Jolly (remanescentes nucleares) no esfregaço de sangue periférico. 1,7,8

0 diagnóstico de esplenose requer um elevado índice de suspeição, sendo de fulcral importância a descoberta na anamnese de um histórico de rutura traumática do baço e/ou esplenectomia. ${ }^{1,7}$ Esta entidade nosológica deve ser considerada no diagnóstico diferencial de patologia maligna secundária da pleura.

A suspeita clinica poderá ser confirmada pela cintigrafia pulmonar com Tc sulfa (99m), exame de alta especificidade na demonstração de tecido esplénico ${ }^{1}$, o qual também é importante na avaliação da progressão da doença. A punção aspirativa por agulha fina não está recomendada devido ao risco de hemorragia. ${ }^{1} 0$ diagnóstico precoce da esplenose evita procedimentos invasivos desnecessários e permite, quando não confirmado, a abordagem terapêutica adequada à situação clínica em causa.

Em suma, salientamos a importância de se suspeitar do diagnóstico de esplenose torácica sempre que exista uma história pregressa de traumatismo toraco-abdominal num doente com nódulos pleurais assintomáticos. Estes constituem, a maior parte das vezes, achados acidentais em exames de 
Figura 2. Tecido esplénico observado na peca cirúrgica

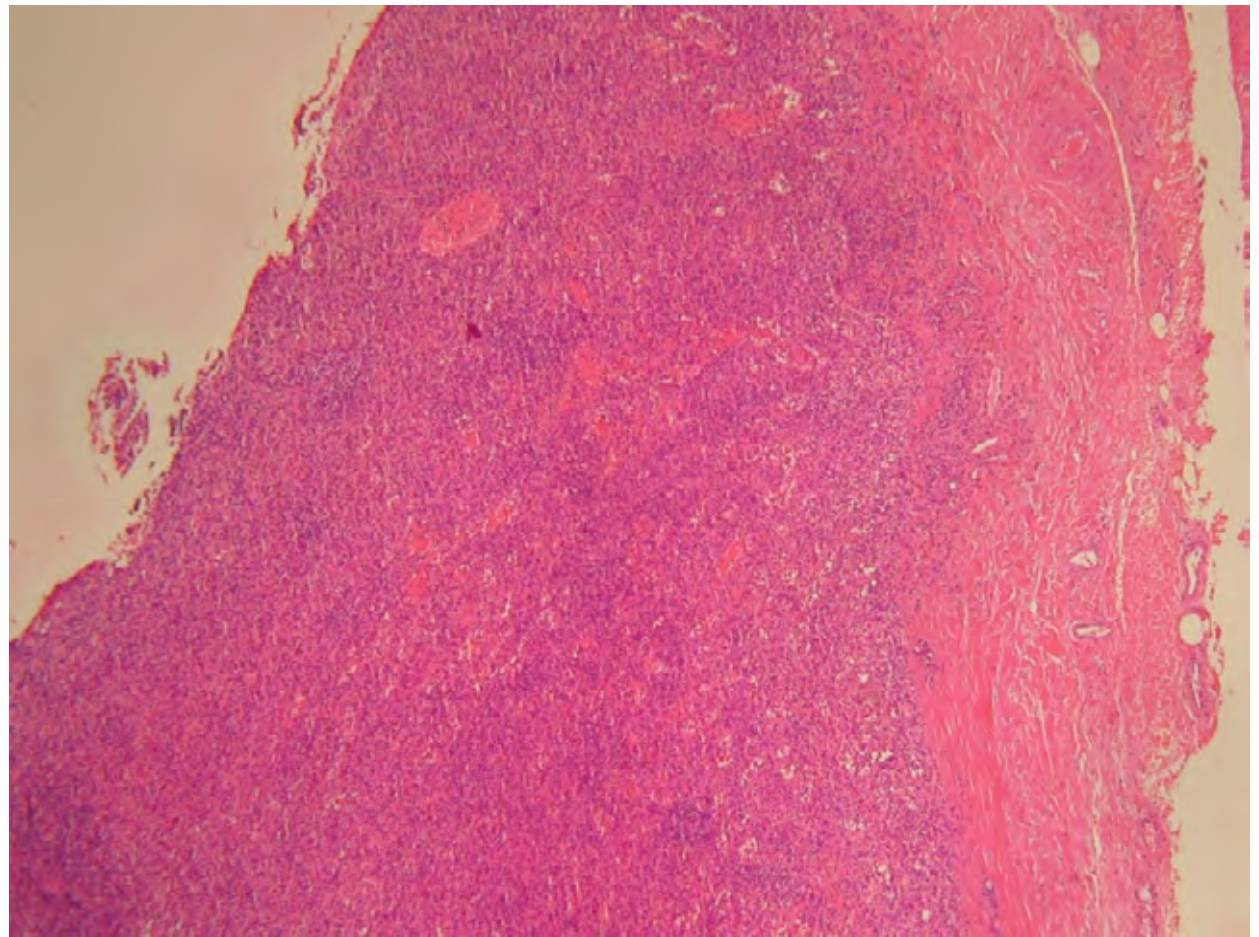

imagem realizados por rotina. Os remanescentes esplénicos não têm indicação para remoção cirúrgica. De facto, eles podem continuar imunologicamente funcionantes e proteger contra eventuais infeções por microrganismos.

\section{REFERÊNCIAS}

1. Vásquez Tineo Sl., García lonso MP., Mendoza Paulini A., Paniagua Correa C., Balsa Bretón MA., Mariana Monguía A., et al. Non-Invasive Diagnosis of Posttraumatic Thoracic Splenosis. Rev Esp Med Nucl. 2011; 30:311-13.

2. Nazar JL., Oddi R., Herrera Vegas D., Freigido S., Begueri Bouquet A. Esplenosis postraumática. Presentación de tres casos. Rev Argent Cirug. 2008; 95 (1-2):1-6.

3. Izquierdo Patrón M. Esplenosis toraco-abdominal: a considerar post-traumatismo esplénico. Rev Patol Respir. 2005; 8:358-60.

4. Bresciani C., Ferreira NR., Perez RO., Jacob CE., Zilberstein B, Cecconello I. Esplenose mimetizando GIST: relato de caso e revisão da literatura. Arq Bras Cir Dig. 2011; 24: $183-85$.

5. Fukuhara S, Tyagi S, Yun J, Karpeh M, Reyes A. Intrathoracic splenosis presenting as persistent chest pain. J Cardiothorac Surg. 2012; 7:84.

6. O-Yurvati AH., Thompson JB., Woods TN. Thoracic Splenosis More Than 40 Years After Thoracoabdominal Trauma. J Am Osteopath Assoc. 2013; 113: 853-56.

7. Quintao Silva MM., Lopes Moreira RC., Souza de Paula I., Rabelo Bernardes B., de Miranda Capanema HX. Relato de caso de Esplenose: diagnóstico diferencial importante em pacientes esplenectomizados apresentando massas abdominais. Rev Univ Vale do Rio Verde 2014; 12: 748-54.

8. Malik UF., Martin MR., Patel R., Mahmoud A. Parenchymal Thoracic Splenosis: history and nuclear imaging without invasive procedures may provide diagnosis. J Clin Med Res. 2010; 2:180-84.

9. Huang AH., Shaffer K. Thoracic splenosis. Radiology. 2006; 239: 293-96.

10. Limonard G., Joosten J., Berk Y., De Kievit I., Zomer S., Keemers M. A 37-Year-Old woman with an incidentally found mediastinal nodule. Chest. 2008; 133:1508-11.

11. Hagman TF., Winer-Muram HT., Meyer CA., Jennings SG. Intrathoracic Splenosis: superiority of Technetium Tc 99m Heat-Damaged RBC Imaging. Chest. 2001; 120 2097-98

12. Normand JP., Rioux M., Dumont M., Bouchard G., Letourneau L. Thoracic splenosis after blunt trauma: frequency and imaging findings. Am J Roentgenol. 1993;161:739-41.

13. Viviers PJ. A case of thoracic splenosis in a post-splenectomy patient following abdominal trauma: Hello Howell-Jolly. Oxf Med Case Reports. 2014; 5: 93-95.

14. Yammine JN., Yatim A., Barbari A. Radionuclide imaging in thoracic splenosis and a review of the literature. Clin Nucl Med. 2003; 28:121-23. 